\title{
Prostate Cancer Prevention Trial
}

National Cancer Institute

\section{Source}

National Cancer Institute. Prostate Cancer Prevention Trial. NCI Thesaurus. Code C16070.

A phase III, randomized, placebo-controlled cancer prevention trial of $>18,000$ men coordinated by the Southwest Oncology Group. The trial will determine the effect of a daily dose of finasteride taken for seven years on the biopsy-proven prevalence of prostate cancer. It is scheduled to be completed in 2004. 